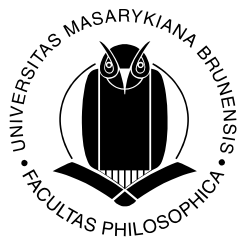

Brno Studies in English

Volume 39, No. 2, 2013

ISSN 0524-6881

DOI: $10.5817 / B S E 2013-2-4$

DARRELl VARGA

\title{
On True Meaning(s) and the Impossibility of Documentary in the Films of Jennifer Baichwal
}

\begin{abstract}
Canadian filmmaker Jennifer Baichwal has made a remarkable series of feature documentaries that have until now received little scholarly attention, though they have circulated widely at film festivals, theatrical screenings and on broadcast television. These films: Let It Come Down: The Life of Paul Bowles, The Holier it Gets, Shelby Lee Adams'Appalachia: The True Meaning of Pictures, Manufactured Landscapes, Act of God, Payback and Watermark operate against the grain of informational instrumentalism associated with conventional documentary. They are playful and meditative explorations of the relationship between human culture, the built environment and forces of nature. This essay surveys recurring themes, strategies and issues across this body of work and situates this filmmaking practice within the oral tradition as described by Canadian thinker Harold Innis.
\end{abstract}

Key words

Jennifer Baichwal; Canada; documentary cinema; chance; truth; representation; Paul Auster; time; oral culture; Harold Innis

In the pivotal moment of documentary filmmaker Jennifer Baichwal's The Holier It Gets (1999), a pilgrimage she undertook with her three siblings (and her husband Nick De Pencier, the cinematographer) to deliver their father's ashes from their Canadian home back to his birth country of India, we see the ashes spilled into the head of the Ganges River but through an oblique frame. The father left India and never expressed his feelings for the place to his Canadian-raised children. They gather to carry out his final wishes but are stranded due to bad weather and mudslides, but also out of a need to sort through difficult questions of place, belonging and value. In that scene on the Ganges, the camera is held at 
a distance, we hear Baichwal's brother sob and we see the ashes as it passes behind the limbs of the family members standing alongside the fast moving water. While this is an intensely personal film, the camera does not invade the private space of the family. It is a recovery not of the body and not simply a picture of the dead; instead the film gives us a space to reflect on the relationship between east and west, family, death, time and the river. Moving water is an important metaphor of time carrying through Baichwal's films, especially with the masterful Watermark, on the very subject of water, discussed later in this essay. Within the logic and presence of The Holier It Gets, these questions of time, mortality and cultural difference remain unanswerable, even as it is important to know the question. These films are journeys that seek answers knowing that these cannot be found, at least in a totalizing way. At the same time, this is not a postmodern disavowal of truth and history. With this image of the father's ashes floating into the Ganges are the seeds of the complex metaphysical questions explored throughout this filmmaker's body of work, questions that are always also riveted to the particular moment in space and time but that these are moments created in the interstices of chance. ${ }^{1}$

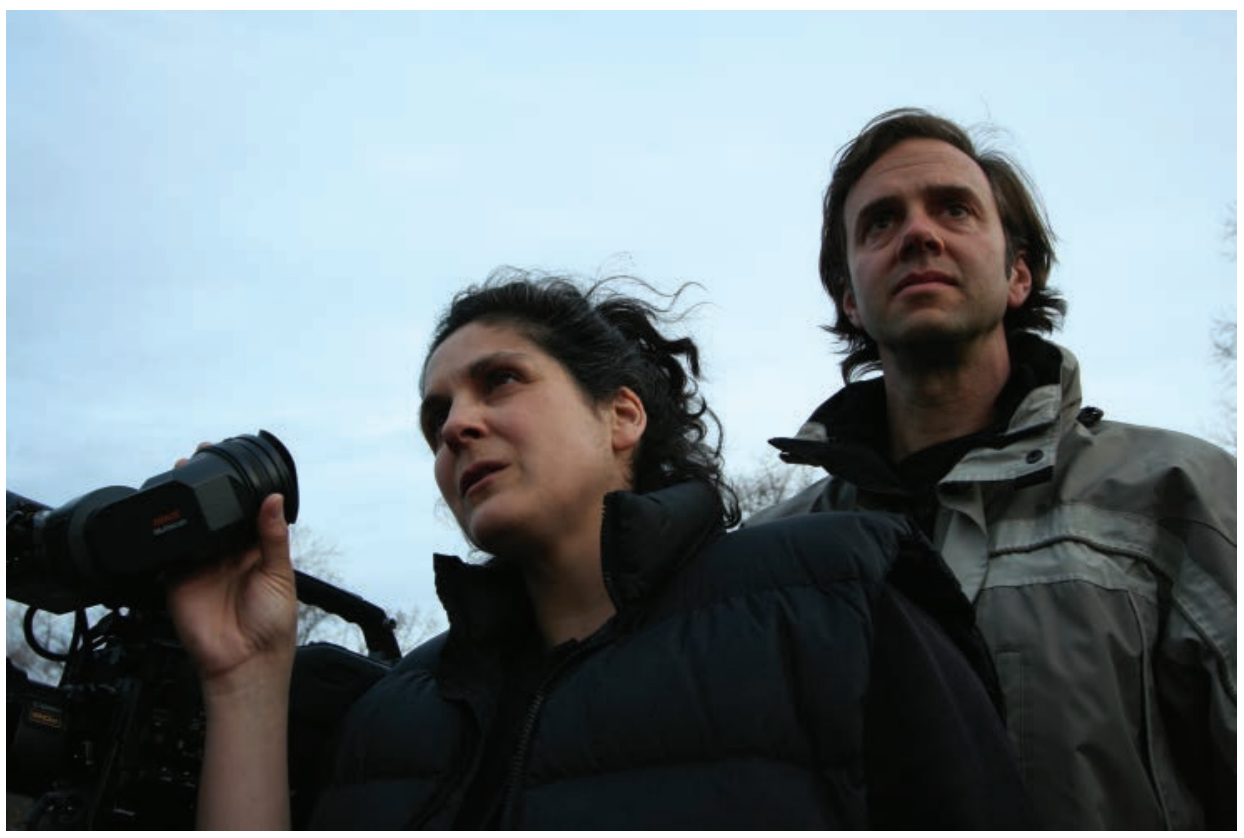

Figure 1. Jennifer Baichwal and cinematographer Nicholas de Pencier, used with permission of Mercury Films

Baichwal's films are not informational, although we learn plenty about the world through them; instead, they are immersive and embodied experiences in a dialectic of thought and geography. The purpose of this essay is not to provide a detailed 
analysis of each of these films; instead, it uses images of space, time and chance across this filmmaker's body of work in order to provoke questions of process and representation. The breadth of these films defies simple summation and while there are ideas in this essay that could be developed into several separate articles, I want this broad sweep across one filmmaker's work to allow an opportunity to reflect upon the complexity of documentary cinema as a form that is at once rooted in the materiality of the world and that can also draw our attention to the ways in which representation enables or reconfigures existing ideas of what is that world. By the naming of this beast "documentary" we are conjuring a contractual order of verisimilitude, but out of this relation comes the abstractions of knowledge. In this way, form and content are inextricably linked, but that documentary is too often struck down by the informational obligations of empiricism. Representation always both reveals and obscures the world. It is in this space and in this tension that ideas emerge, a tangle of the necessary and the impossible that is the journey of non-fiction filmmaking.

To be struck by lightning is the quintessential act of randomness or, as some would say, an Act of God - the title of Baichwal's 2009 film. In this case, the event is an opening for metaphysical reflection grounded in the space of experience. The American writer Paul Auster serves as the film's primary narrative voice. His work is entirely structured around randomness and chance along with the desperate but probably futile efforts we undertake to ascribe meaning to the disconnected events and interactions of daily life. In a dynamic culmination of stories from various parts of the world of being struck by lightning and set to the chaotic improvisations of music artist Fred Frith, Auster reads a story originally released under the soul-searching title Why Write, relating a true experience from his boyhood years at a summer camp in upstate New York (Auster 1992: 66-71). Truth remains a tricky term when it comes to representation, whether in writing or on screen. In this case, we are invited to reflect on authorial presence and voice implicitly declaring the impossibility of not writing - and thus transforming experience - in the face of trauma. Ideals of documentary objectivity no longer have the same resonance as when John Grierson conjured the word, but this is precisely what makes the form interesting and vital - as a subjective process of representation that nevertheless maintains an integral relation with the world. The form is distinct because, as Bill Nichols explains, it does not provide an imagined world as in fiction film (Nichols 2001: xi) and for this reason a complex web of social responsibility is set in motion. Auster's group of boys set out on an afternoon hike, get lost in the woods and caught up in a tremendous storm, so fierce it could, as Auster says, be "ripped from the pages of the bible". The boys decide to crawl under a barbed wire fence to an open field when Ralph, just in front of Auster, stops moving. In the desperation of rain, mud and confusion, they drag Ralph through but it is too late, he has been killed by the sudden blast of electricity. The film does not try to explain lightning as if to tame the experience by rationalization; instead, it is interested in the human desire to make meaning out of the chaos and violence of nature. We cannot know the truth directly, we 
were not there when Ralph took his final breath, nor are we inside the mind of the boy as witness. We only have Auster's gaze at the camera when he finishes reading, as if to say I was there, but also to refuse the pretense of interpretation or the "magical thinking" of divine rationalization.

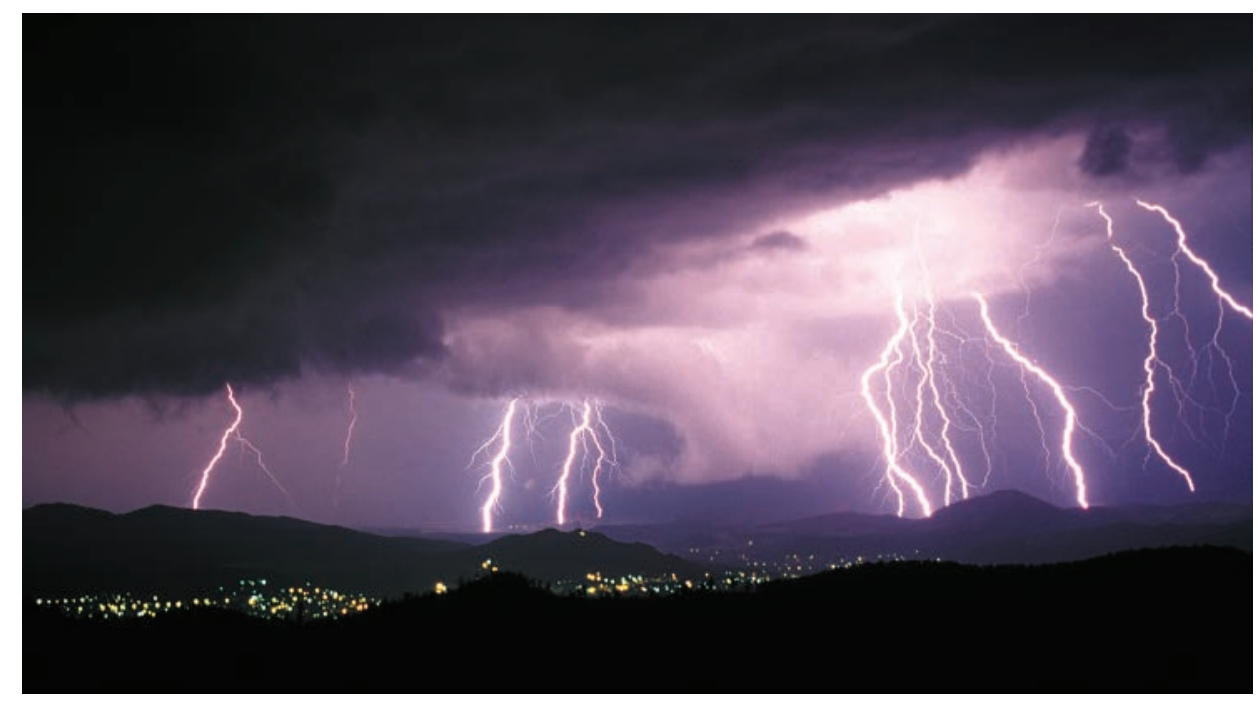

Figure 2. Act of God, used with permission of Mercury Films

Musician Fred Frith is asked to create an improvisation based on the idea of lightning and in an earlier scene we see him creating music while his brain frequencies are being monitored in his brother Chris Frith's laboratory. ${ }^{2}$ Science is associated in popular discourse with empirical truth yet the scientist does not speak of absolute knowledge but within a frame of temporal contingency. The idea is that the storm inside our skulls caused by the firing of neurons when the brain is engaged creatively mirrors the energy of a lightning storm. For the scientist, the complexity of the human brain, on a magnitude with the entirety of the solar system, is suggestive of our potential to understand the world even as we continue to grapple with questions. Throughout Baichwal's films, we are taken from the particular moment to the big picture in a way that is cinematically seductive but that also confounds easy explanations. The scientist seeks to quantify the pulse of electric energy in the brain while the artist depends on the indeterminate, on the unknown. This is not to romanticize the artist as visionary but to allow for a process of discovery outside of instrumental reason - a way of thinking that is the dread of the documentary as storyteller (and of the scientist who knows that the unintended consequences of any study are often the most interesting). The way we see Frith perform in the film is both carefully composed but also allowing for randomness and he describes his improvisational process as storytelling, evoking 
an oral rather than literary approach, where accidents are always an opportunity. We see extreme close ups of the artist's hands and at one point the powerful image of metal chain dragged across his guitar strings - an image of violence, bondage and strength machined against the grinding of the strings. His performances transpose the ideal of chance onto the texture and materiality of found objects. "Chance" in Auster and Frith is not just the random collision of one event upon another; it is the way a juxtaposition of experiences transform perception located in the impossible zone of documentary; that is to say, between meaning and randomness. These films are not cast in the model of the Griersonian documentary with its problem and solution structure. Act of God is interesting precisely because it cannot answer its main question of why lightning strikes this person and not that one. After all, why not both of them? Why not us as we sit back and watch? After all, there is no such thing as a safe distance when it comes to nature.

The act of writing is to make order out of chaos, to reconcile experience with narrative while maintaining the sense of wonder. It is carried out not in the face of the unknown, implying a hidden meaning or order to events, but in a compulsive ordering of words at the limit of meaning and with a primary concern with process. Auster has described his own writing in visceral terms related to the physicality of working with a pen: "You feel that the words are coming out of your body and then you dig the words into the page" (Wood 2003). The image has an affinity with the not-very-glamorous labour of documentary: small budgets, deferred wages, economy travel, walking with the camera, digging into locations. It is through this physical process that we encounter a liminal space of meaning that folds back upon our own lived reality. The film also points to the irreconcilable space between word and image - important for a filmmaker invested not in literary adaptation but in the cinematic exploration of the process of writing. This cinema involves expression rather than illustration, evocation rather than explication; after all, the subject is the very force of nature that, like death, is ultimately unrepresentable (Sobchack 1984). Auster's gaze at the camera is neither passive nor emotive; it is direct in a way that defies the empiricist intentions of Direct Cinema even as that mode of documentary approaches the physicality of representation with the greatest of intensity. Auster's expression offers a sense of relief from working through the labour of writing. What we see in the conclusion of Act of God is forged in the confluence of sound, memory and the desire for narrative. The wonder of story is that it is found precisely in the gap between truth and representation, with the potential for temporary relief with the audience in the act of reception.

Some stories cannot be completed without the spilling of blood. Payback (2011) a film version of Margaret Atwood's non-fiction book Payback: Debt and the Shadow Side of Wealth (2008) has the tag line "Some debts can't be paid with money." Here, we move in broad strokes from the individual to the global - a stark image midway through Baichwal's film is from a helicopter flying over the Deepwater oil rig explosion in the Gulf of Mexico (in April 2010), showing us a hard line on the water where one side of the image is blue, the other is a thick 
brown sheen of oil. It is like an absurd planetary ledger book wavering on the skin of the earth. Payback is not telling us about economics; rather, it uses debt as metaphor of limits, that we have pushed our bodies and the planet to an ecological end. By linking body and planet I am both indicating the poverty and indentured servitude of vast numbers of people to the material benefit of the west as well as the integral bond between living bodies and a healthy planetary ecosystem. The film invites us to think about the ecological deficit of rich countries consuming more of the ecosphere than can be paid for via sustainability and where money, the very precondition of space and empire, is but an illusion standing in for debts that cannot be paid or, in the case of environmental disaster, cannot be papered over with money.

To understand this concept in the gritty reality of everyday life, Payback brings us to the story of a blood feud in remote northern Albania. It is a dispute over property boundaries but with the baggage of masculinity and violence produced out of an ancient code of law and adjudication (The Kanun Code) embedded in local tradition as a way of formalizing revenge. ${ }^{3}$ The Code is a traditional Albanian set of laws, transmitted orally from ancient times, for social regulation over such matters as marriage, work, property, crime and honour, really every aspect of medieval life. In remote villages, the Kanun supersedes whatever provincial or national juridical system may formally be in place. In the film, we learn of a blood feud that began over a property dispute that escalated into attempted murder. If this set of laws once helped maintain communal order, what we see in the film is simply pure revenge. It was a system of local dispute resolution that was suppressed under communism and has reemerged after the fall of the Soviet Union, like a bad seed fermenting in the logic of tradition alongside the promised abundance of capitalism. Under the Code, the victim is allowed to seek revenge on the perpetuator, and on any male member of his family. This revenge sanctions murder and, from what we see within the film, has no logical alternative because the victim and his family express no willingness to otherwise mediate the dispute or in granting forgiveness. The resolution of the original property dispute falls to the background as both sides dig in with their version of truth (something the film is likewise unable to interpret one way or another) and the logic of revenge takes over. As a result, the family facing this revenge is confined to their small compound. Here, children grow up with no place to go yet we see a young boy proudly pointing to the Albanian flag mounted above his parent's bed.

Inasmuch as I would argue that the documentary film process is a manifestation of oral tradition, this story is a reminder that we cannot approach orality through an innocent or romantic frame. With this concept of oral culture I am drawing upon the ideas of Harold Innis, the Canadian political economist and communications theorist whose ideas formed in the 1930s and 40s set the stage for the bold proclamations on media and literacy by Marshall McLuhan in the 1960s. The isolation and violence found in this remote Albanian community gives the lie to the utopian fantasy of McLuhan's media-connected global village. Innis was more nuanced in understanding culture as forming out of the conflu- 
ence of spatial and temporal biases, with the spatial associated with writing and the temporal associated with orality. The spatial bias of text facilitates the expansion of empire because it enables the standardization of expression and the exercise of written law across distances, while an oral framework depends on proximity and immediacy within the maintenance of tradition. Innis's concern was with the formation of monopolies of knowledge that would inhibit expression, and that this occurs through particular uses of technology, beginning with the standardization of expression that comes with the alphabet. His writing is enigmatic and a challenge to apply to cinema analysis, since he never went to the movies. My point in making this reference is to understand cinematic representation in the broad context of culture and power, and this is how Innis presents the spatial and temporal bias. "Lack of interest in problems of duration in Western civilization suggests that the bias of paper and printing has persisted in a concern with space. The state has been interested in the enlargement of territories and the imposition of cultural uniformity on its peoples, and, losing touch with the problems of time, has been willing to engage in wars to carry out immediate objectives. Printing has emphasized vernaculars and divisions between states based on language without implying a concern with time. The effects of division have been evident in development of the book, the pamphlet, and the newspaper and in the growth of regionalism as new monopolies have been built up" (Innis 1951: 76).

The Albanian blood feud is a cautionary tale of the idealization of orality; the participants are trapped with no way out, for the ideal of compromise does not exist within the use of this tradition in the $21^{\text {st }}$ century even though compromise is part of the original Code. Nevertheless, I would like to make the case for the affinity of orality with documentary insofar as non-fiction filmmakers are concerned with strategies and technologies of communication related to narratives of power and can reflect upon and even subvert the prevailing order of discourse. In this way, the long-form documentary functions against the spatial bias fixed with the one-way flow of mass media, even if it engages with the prevailing system for financing, itself entirely bound up with the commercial media marketplace. The oral practice of documentary filmmaking structurally inhibits the emergence of monopolies of power since speech remains dependent upon immediate relationships in time, and this foundational condition is important in the production process and in reception. In Baichwal's films we witness this process through a dialectical structure from the global to the local, the universal and the particular, following Aristotle's Poetics where the particular is to be subordinated to the whole.

Payback begins with a slow pan over the mountainous Albanian landscape and the sound of hands on a keyboard, an audio reminder of the physical and narrative processes in making space and culture, and we then hear from the two men at the centre of the feud. Debt is understood not as dry financial exchange but as something tied to life and society. While we may be shocked by what the men say, the point is not to cinematically highlight a case of primitive barbarism but to set this story in relation to the structuring force of economic relations. One could say that it is a flashpoint for the barbarity of capitalism. The film returns to Atwood, now 
performing her Payback text as part of Canada's prestigious Massey Lecture Series produced for the resilient oral medium of public radio in front of a live audience. The talk begins with an old joke in response to a comment about pleasant weather: "We'll pay for it later!" The joke casts back to a grim Christian notion of guilt and punishment as consequence of pleasure - a debt to be revenged! Ideas of pleasure, even related to so-called natural phenomena like a day of sunshine, only ever exist for human beings in relation to how we think about and describe them.

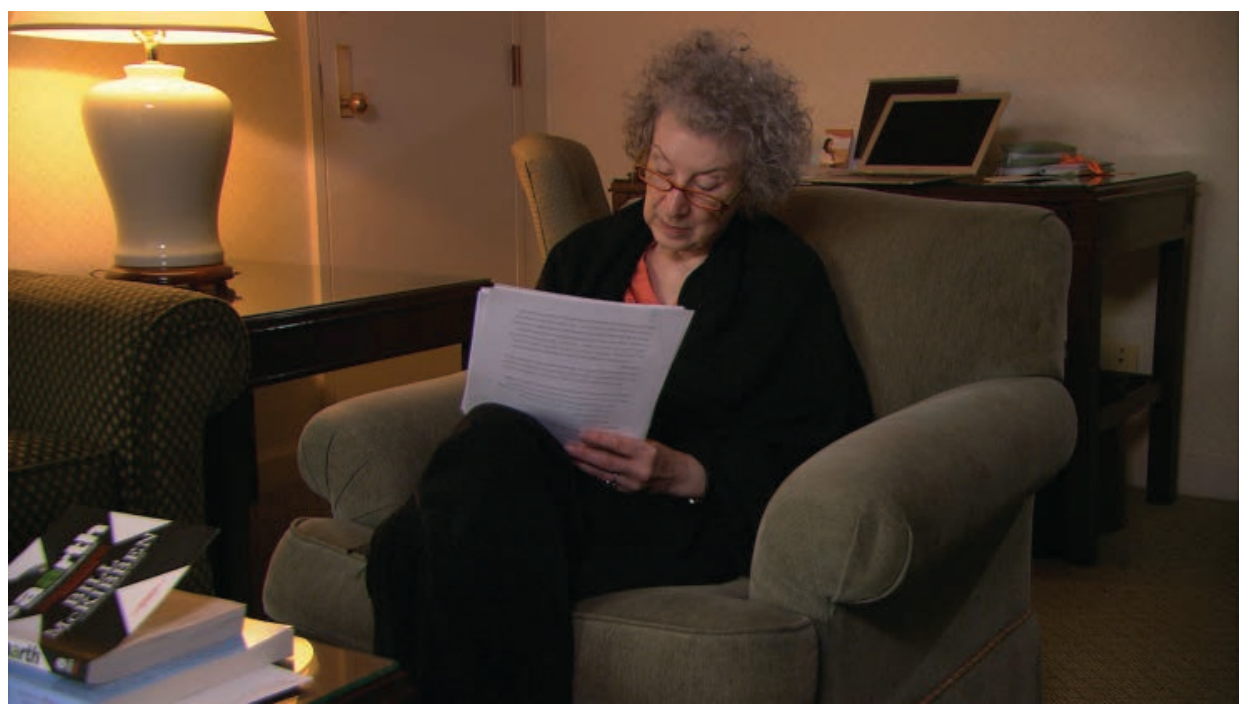

Figure 3. Author Margaret Atwood in Payback, used with permission of Mercury Films

The film takes up this fact concretely when it returns to the environmental disaster in the Gulf of Mexico that is really an image of the cost of a particular industrial-capitalist claim to nature. Atwood posits the idea of how the guilty is obliged to "pay his debt to society" and the film explores the image of prison and the idea of punishment as social redemption. However, the fires on the water of the Gulf of Mexico illustrate how all of us are imprisoned by the prevailing economic frame through which social order is managed. This can change if we imagine the concept of debt in less punitive ways and against the grain of the neoliberalist fantasy of trickle down economics. Notice, as Atwood says, "The metaphor is not of a gushing waterfall, but of a leaking tap." The film concludes with a sharp welding of the literary and the oral, with various characters seen in overlapping shots, reading a passage from the book illustrating Dickens' Scrooge coming to terms with the madness of economics in the $21^{\text {st }}$ century:

"Maybe we need to count things, and add things up and measure things in a different way ... Scrooge climbs out of his bed and goes to the window. 
There's the world. It's very beautiful, what with the trees and sky and so forth. It used to look solid, but now it appears fragile, like a reflection on water... 'I don't really own anything,' Scrooge thinks. 'Not even my body. Everything I have is only borrowed. I am not really rich at all. I am heavily in debt. How do I even begin to pay back what I owe?'”

The scene is formally brilliant, with overlapping voice fragments and a weave of languages, but the film also places characters, rich and poor, in a constellation in a way that both recalls Marx's dictate that "everything that is solid will melt into air," but that also suggests the revolutionary potential of everyday speech.

How do we speak about what we see? What happens to this speech-sight relation when mediated by the photographer's camera? How do we understand this process when the photographer's gaze is further mediated via cinema? Filmed in the isolation of the Appalachian region of Kentucky in the southern U.S., Baichwal's The True Meaning of Pictures: Shelby Lee Adams'Appalachia (2004) explores photographer Adams in his project of photographing rural Appalachian residents. The dominant criticism of Adams is that the pictures do nothing but perpetuate stereotypes of "hillbillies". To emphasize this concern, the film cuts to an excerpt from the John Boorman thriller Deliverance (1972), a film recognized by the National Film Registry of the Library of Congress, but that perpetuates the stereotype of inbred, uneducated and violent backwoods locals. Our understanding of the subject is shaped through reference to other media representations. Shelby Adams, in turn, describes his own immediate connection to place and people with an affirmation of the real: "I'm trying to show what is really here. It is a hard life. I don't want to romanticize or idealize." He goes on to describe part of his own childhood spent in this rural area, though not amidst the poverty shown in his images. With respect to his subject position: "They accept me because I accept them. It's that simple." The title of the film comes from a comment made by one of his subjects in defense of the photographs, that they depict the hard life in the region. The context for these pictures, and Baichwal's filming of the process of picture taking, is a history of well-intentioned journalism that focuses on the poverty of place (perpetuating local stereotypes) at the same time that there is a massive increase in the capitalist exploitation of cheap labour in regional strip mining. What unfolds is an examination of competing ideas of value as located at the margins and within what is largely an oral culture. While the middle-class gaze, armed with data and text, may express a safe degree of sympathy with the unchanging trajectory of poverty, what Adams is doing is closer to Brecht, showing us an unadorned social reality that we have to interpret. The power of these images, and the complexity of the relationship between photographer and subject make it impossible for us to turn away, even as it is just as impossible to know the "truth" in absolute terms.

The film opens with the tree-covered landscape of Kentucky overlaid with the frantic, almost breathless sounds of evangelical preaching. Later, we see an archive video taken by Adams of snake handling within a sect of the Pentecostal 
church. While this practice is illegal in public forums, it is present in private homes on the margins of the social order. The belief involves speaking in tongues and a literal interpretation of the bible whereby belief shields the subject from poison. Later, we see a man severely wounded by snakebite but determined to continue the practice. Without diminishing the complexities of religious belief and the very real dangers, there is an affinity here with the processes of interpretation unfolding across the film - a process that involves exercising agency over the act of looking through which emerges questions of home and belonging. It is the idea of legitimacy, related to point of view, put to Adams by his critics. We see an urban crowd inspecting the photographs, but also immersed in the wine and cheese of gallery chatter. On the one hand, the images suggest a search for a "true" vision of Appalachia, as it may have existed a hundred years ago. Adams, however, claims that nothing is staged, though he talks about his compositional strategy in classical art history terms. We see the photographer carefully arranging his subjects under artificial lighting before his large format camera. This discourse at once signals a distance from documentary objectivity and reminds us that the process of mediation is always produced at a calculated remove from the real. It is in this discourse of calculations that arises the key tensions of the work.

An art critic condescendingly states that in order for the images to assert legitimacy, they must be presented explicitly as the artist's subjective expression of Southern Gothic, but by no means can they serve as documentary representation. This comment is key to the problem of contemporary documentary and is based on the privileged artworld assumption that documentary is always defined by being without subjectivity, an idea made within prevailing institutionalized biases of representation irrespective of actual existing practices. The art critic's perspective is founded on a pejorative assumption that the subjects of these images cannot possibly understand the true meaning of these sophisticated photographs, that they have no perspective except as victim. He also asserts the controlling desire to categorize the images within the Gothic tradition, rather than attempt to see and engage without the standardized limits of the critical art historical convention. Meaning and interpretation is claimed as the domain of the artworld professional - educated through mastery of the written text. All of this is attached to the persistent idea that documentary must have a transparent relation with reality. This relation has historically been deployed in political complaints against social-reform oriented image making, for instance in conservative attacks against New Deal photography in 1930s America (Morris 2011: 123-185) and the turn in British television documentary in the 2000s as detailed by Brian Winston (2008). What the film wants us as viewers to think about is whether meaning or "truth" comes from the subject, from interpretation or whether it is something exercised with the artist's prerogative, where claims to objectivity are but one tool in the process of making the work. The viewer is confronted in a visceral way by these images and the filmmaker sets up a tension that is sympathetic with the Appalachian subjects but without resolving a question that remains central to documentary: How is it that we look at the things we look at? 
Manufactured Landscapes (2006) is at once about the way we see the world and an intense gaze at the individual figure within a landscape that is entirely a built environment. The opening shot is a continuous track, running for over eight minutes, a bit less than the run of a roll of $16 \mathrm{~mm}$ film, through a massive Chinese factory. It is a sublime space, both immense but also strangely claustrophobic, with photographer Edward Burtynsky breaking into the soundtrack at the five minute mark to describe a desire to see nature. Burtynsky, the subject of the film, is a photographer working in large-scale images of the built environment, drawing our attention to the human transformation of nature. Nature and the environment are not the same thing; the former being all of organic matter while the latter relates to the cultural interface with nature. It is on the human face where this tension is realized. Later in the film there is an extended shot, without commentary, on the face of a factory worker while she assembles tiny components, her eyes focused intently on the job. No words are exchanged (and none were allowed between filmmaker and workers within the factory) but none are necessary to foster our understanding. Her job is to make that which is disposable and later we see vast heaps of scrap metal and the tedious work of sifting the elements in order to retrieve valuable metals. The film is interested in exploring the contradictions of scale with Burtynsky's focus on the grand gesture and Baichwal in search of the personal stories present within the landscape. Masses of people make tiny components that end up as mountains of waste - this is the new landscape of civilization.

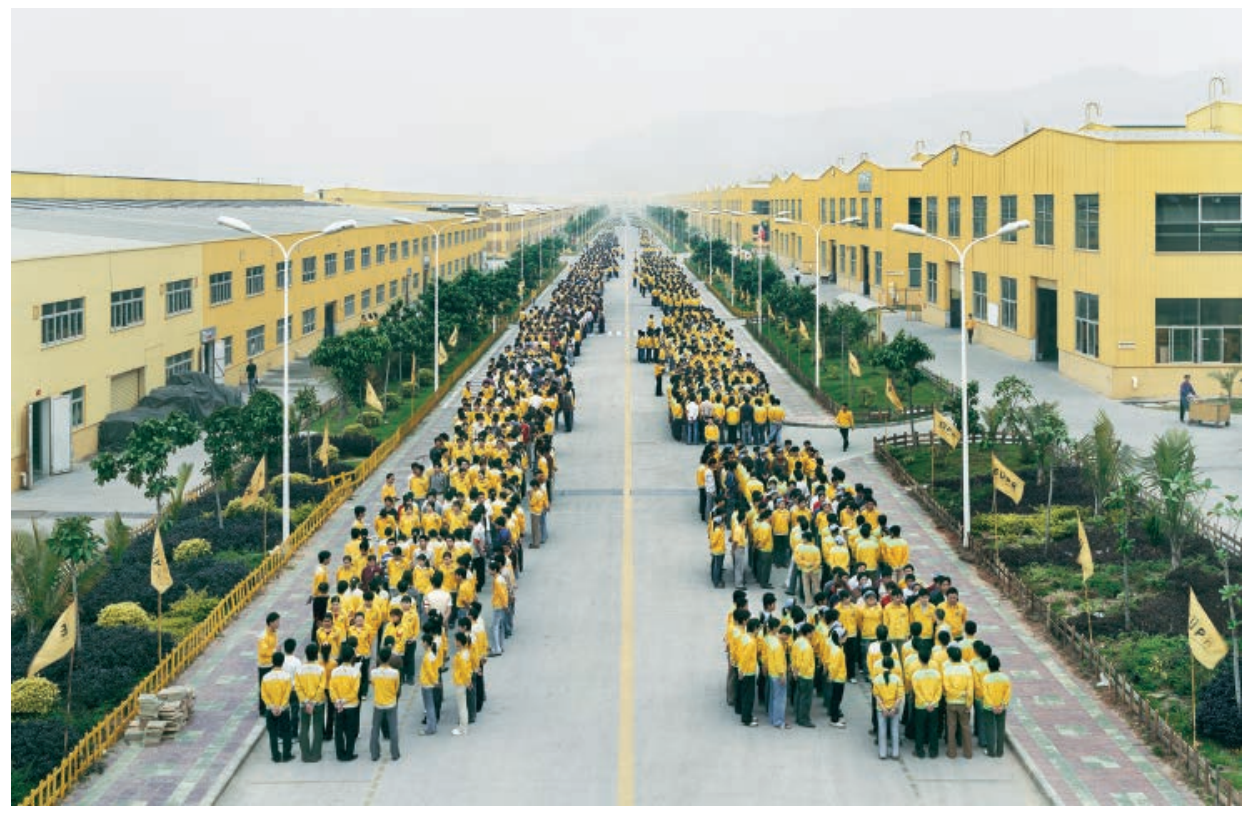

Figure 4. Manufactured Landscapes, photograph by Edward Burtynsky used with permission of Mercury Films 
There is an affinity between Burtynsky's aesthetic transformation and the plea for imagination as supplement to reality as voiced by Paul Bowles in Let It Come Down (1998), Baichwal's film biography of the writer. With this sentiment, these films confront conventional information-oriented assumptions of documentary through a process that is not simply description but is visual exploration. The Bowles film, however, is largely structured upon a lengthy interview with the author, near the end of his life, as he leans back on his bed elegantly smoking kef. This is a film about close-ups and the presence of the face in relation to creativity, leaving us with the challenge of reading the face of an author relating the violent desire founded in his writing. Baichwal's approach recalls Walter Benjamin's description of the spatial and temporal transformative potential of cinema: "By close-ups of the things around us, by focusing on hidden details of familiar objects, by exploring commonplace milieus under the ingenious guidance of the camera, the film, on the one hand, extends our comprehension of the necessities which rule our lives; on the other hand, it manages to assure us of an immense and unexpected field of action. [...] The enlargement of a snapshot does not simply render more precise what in any case was visible, though unclear; it reveals entirely new structural formations of the subject" (Benjamin 1968: 236). Benjamin was inspired by the revolutionary potential of Soviet montage and while the films I am discussing do not follow this political lineage, there is nonetheless a transformative urgency in a documentary grounded in a process of looking - the intensity of a gaze without explanation, but one that is also aware of the essentialist limits of showing the world as if any one gaze can be true.

Outside in Tangiers we see the tight confines of corridors, a maze of murky passageways with no clear lines of flight (this is also the climax of Bertolucci's 1990 adaptation of Bowles' novel Sheltering Sky), as metaphor of the artist's veiled pursuit of gay desire and his hesitation to speak of true meanings. The enigmatic Bowles eludes representation: "If I described myself, that would mean that I exist. I don't believe that... All my work is behind me." This artist can only exist through his work - through the product of imagination and the labour of writing. This film structured around the close-up is really about the subject refusing closeness - he describes being in love as abnormal, like schizophrenia. A privileged moment in the film captures a reunion with Bowles, Allan Ginsberg and William S. Burroughs in a New York City hotel room - these icons of the Beat Generation now as frail old men speaking of writing and meaning (or in the case of Bowles, according to Burroughs, the absence of meaning). These now respectable writers collectively expressed the veiled darkness and violence of America, the unheimlich of capitalist order - a culture described by fellow Beat writer Jack Kerouac as mostly being "shamed into silent conformity" (Morgan 2010: 134).

Let it Come Down does not confront these social-political conditions; rather, it traces the subject's self-imposed exile as necessary fuel for his art, taking cover with an inner process. In contrast, Act of God takes an immersive and performative approach. We see this in an important sequence with James O'Reilly, author 
of a theatrical monologue called Act of God. O'Reilly's story is similar to that told by Paul Auster, relating an experience as a young man being caught outdoors during a ferocious thunderstorm and witnessing a lightning strike that killed a friend. We are viscerally drawn into the experience by his performance in the wooded location of the original event. Like the idea of "truth," terms such as "original" and location stick to documentary like glue. The point, however, is that here the space is deployed not for instrumental value but in a way more akin to what Werner Herzog, in his infamous Minnesota Declaration, calls "ecstatic truth" against the now canonical cinema verité approach, a method Herzog disdains as "the truth of accountants" (Ames 2012: ix). We see O'Reilly throwing himself to the ground in mimicry of the shock of the event, and then running for help and acting out his dodge from one side of the path to another as if being chased by the villains of a Hollywood war movie. It is the need for narrative in the oral tradition that brings meaning to experience in spite of the key lesson of nature, which is we are entirely insignificant in the face of the force of lightning. Story becomes relief from the real; it is the transformation of experience.

This transformative process, engaging the abstractions of the universal out of the particular, is fully manifest in Watermark (2013), co-directed with Ed Burtynsky. The photographer wanted to make a film in support of his major photography project Water and turned to his friend Baichwal for guidance (Burtynsky 2013).

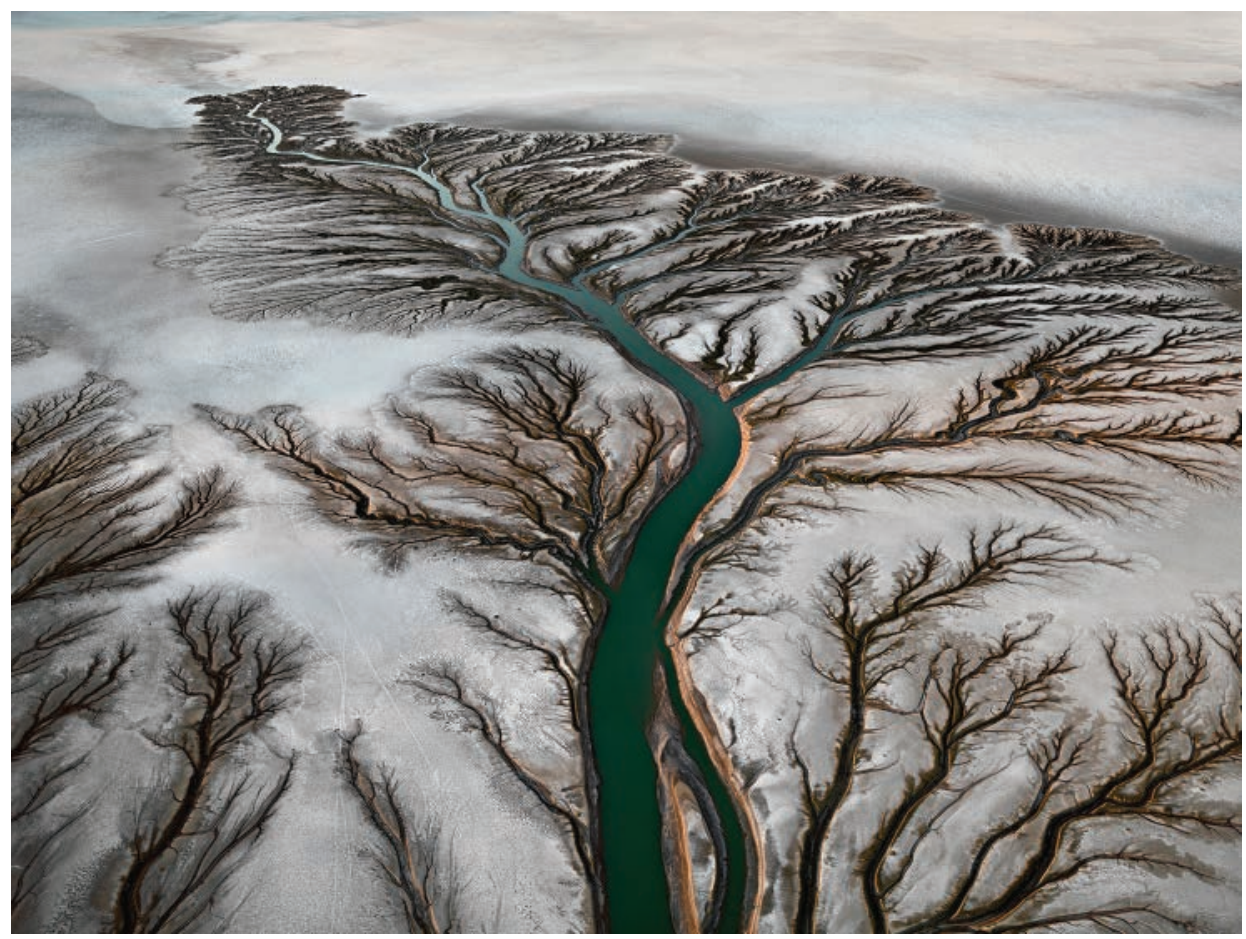

Figure 5. Watermark photograph by Edward Burtynsky, used with permission of Mercury Films 
Where Manufactured Landscapes is the filmmaker's film about the photographer, with Watermark they work in collaboration but in some ways Burtynsky remains the subject of the film (we even see copies of his book rolling off the press). A question of authorship, haunting the edges of Manufactured Landscapes is now brought into the light. These artists have a very distinct approach to landscape, a tension that is never fully resolved since it relates to what, from my viewing perspective, is suggestive of differing conceptualizations of nature. Burtynsky works in the large scale of the landscape tradition while Baichwal is more in tune with the fact that the environment is always already transformed by culture. From this perspective, the process is not an archeology of vision tracking a loss of an ideal nature but an approach to narrative rooted in the oral tradition whereby spaces and places are always already made by human intervention. ${ }^{4}$

This interest in the human detail is strikingly realized near the end of Watermark in a scene amidst the rice paddies of rural China with a focus on a young man who is his family's water guard - ensuring that the family's plot receives its allotment of water, that water is not diverted to another field. With his sparkly pink hat and endearing presence, the subject could have stepped off the screen of any number of New Wave movies. He walks with cell phone in hand, eventually leading the crew to a dinner scene with his family, but the young man yearns to see the world, to escape the regime of traditional work. Throughout, there is a contrast between tradition and the modern, and while the former is by no means idealized (we see the hard labour of leather tanning in Bangladesh and witness the toxic chemicals pouring forth), the modern is associated with the absurd whether in the disco-dance of Las Vegas choreographed water fountains or in the land swindle behind the building of the Los Angeles aqueduct. The camera focuses on the rusty pipes spraying water onto the bed of Owen's Lake, once a vital source of California water but drained in 1924 in the building of the aqueduct. In the absurdist logic of the capitalist relation with nature, this lakebed now has to be irrigated in what is called a "billion dollar plumbing project" because it has become the largest source of dust pollution in the United States (water is continually pumped and sprayed to keep down the dust). The scale of this undertaking recalls the scenes with the huge population of immigrant Mexican labour toiling on the irrigated tomato fields in Payback. In both cases, the logic of exploitation gives shape to culture and environment.

Watermark opens with abstract images of murky water created by the purging of silt caught in the hydroelectric turbines on the Yellow River in China - it is at once like a natural storm or an image of creation, but also tourist spectacle with spectators flashing cameras from behind a guardrail. This is the tension of the film - that we are in awe of water, but that our exploitation of this resource enacts a transformative process, the consequences of which we do not confront. Likewise, so much of the oceans are dead, but the film mostly hovers over the majesty of water rather than the dirt. The film provides an image of release in its conclusion, an extended shot that mirrors the duration of the opening of Мапиfactured Landscapes but now in the open space of the Canadian north. The cam- 
era is mounted on a helicopter expertly piloted through the winding valley of the Stikine River, the immense watershed of northern British Columbia pouring forth glacial water. It is an image of purity that offers the relief of hope through aesthetic beauty, but the film leaves us with the difficult question: how will we attend to the things we have done to this world? These films cannot resolve these issues; instead, they invite us to look closely at the world, from the specificity of detail to the abstractions of knowledge, from the dynamics of space and empire to the possibilities or time and orality that is the documentary.

\section{Notes}

1 The convention of Film Studies is to refer to the director as author, though this shorthand obscures the important contributions of other key creative workers. Not the least, in these films, is Baichwal's producing partner and cinematographer Nick de Pencier. On Manufactured Landscapes the cinematographer is Peter Mettler.

2 Chris Frith is Professor Emeritus at the Wellcome Trust Centre for Neuroimaging at University College, London.

3 The Kanun Code is the backdrop of a fiction film called The Forgiveness of Blood, Dir: Joshua Marston, USA, 2011.

4 Some of my insights into Baichwal's process come from conversations with the filmmaker on the occasion of her visit to NSCAD University in September 2013. Any misinterpretation of her process remains this author's responsibility. The filmmaker's production company website is: mercuryfilms.ca

\section{References}

Ames, Eric (2012) Ferocious Reality: Documentary According to Werner Herzog. Minneapolis: University of Minnesota Press.

Auster, Paul (1992) The Red Notebook: True Stories. New York: New Directions.

Benjamin, Walter (1968) "The Work of Art in the Age of Mechanical Reproduction." In Arendt, Hannah (ed.) Illuminations. Trans. Harry Zohn. New York: Schocken.

Burtynsky, Edward (2013) Water. Göttingen: Steidl.

Innis, Harold A. (1951) The Bias of Communication. Toronto: University of Toronto Press.

Marx, Karl and Friedrich Engels (1970) The Communist Manifesto. New York: Pathfinder Press.

Morgan, Bill (2010) The Typewriter is Holy: The Complete Uncensored History of the Beat Generation. New York: Free Press.

Morris, Errol (2011) Believing is Seeing: Observations on the Mysteries of Photography. New York: Penguin Press.

Nichols, Bill (2001) Introduction to Documentary. Bloomington: Indiana University Press.

Sobchack, Vivian (1984) "Inscribing Ethical Space: Ten Propositions on Death, Representation and Documentary." Quarterly Review of Film Studies 9 (4), 283-300.

Winston, Brian (2008) Lies, Damn Lies and Documentaries. London: BFI.

Wood, Michael (2003) "Paul Auster: the Art of Fiction" (interview). Paris Review 178, Fall 2003. Accessed on-line: www.theparisreview.org. 
Darrell Varga is Associate Professor and Canada Research Chair in Contemporary Film and Media Studies at NSCAD University (Nova Scotia College of Art and Design) in Halifax, Canada. His recent documentary film Fire, Ice and Sky is an essay on time, landscape and storytelling (available as video-on-demand at snagfilms.com). He is the author of many publications on Canadian cinema, including the forthcoming Shooting in the East: Filmmaking on the Canadian Atlantic.

Address: Darrell Varga, NSCAD University, 5163 Duke Street, Halifax, B3J3J6, Nova Scotia, Canada. [e-mail: dvarga@nscad.ca] 